\title{
EL MANUSCRITO HALLADO Y EL ALEJAMIENTO DEL YO EN DOS AUTORES CONTEMPORÁNEOS: JOSÉ JIMÉNEZ LOZANO Y VICENTE LUIS MORA
}

\author{
Raúl Enrique Asencio Navarro \\ Universidad Complutense de Madrid \\ Facultad de Ciencias de Filología \\ https://doi.org/10.18778/8220-195-6.25
}

\section{Resumen}

José Jiménez Lozano y Vicente Luis Mora parten de concepciones de la literatura si no opuestas, sí muy dispares, y, sin embargo, han encontrado un punto de confluencia en el empleo del tópico del manuscrito hallado. Aunque por razones distintas, ambos han encontrado en él una técnica muy rentable para separar el yo biográfico del sujeto narrativo. En el presente trabajo, trataré de esbozar las poéticas de ambos autores, es decir, dilucidar sus puntos de partida, para luego analizar de qué manera se apropia cada uno de dicho tópico. Dada la extensión de este trabajo, tan solo repasaré dos obras de José Jiménez Lozano -Sara de Ur (1989) y Libro de visitantes (2007)- y la novela de Vicente Luis Mora Alba Cromm (2010).

Palabras clave: José Jiménez Lozano, Vicente Luis Mora, manuscrito hallado, narrador, novela siglo XXI.

El manuscrito hallado es una técnica narrativa abundante y recurrente en toda la historia de la literatura occidental. Ana L. Baquero Escudero lo define como una "una estrategia por parte del autor para encubrir la ficcionalidad de su obra y mostrarla bajo pretensión de autenticidad histórica" (Baquero, 2007-2008: 249). 
Esta definición resulta muy útil si pretendemos aproximarnos a los libros de caballerías, que apelaban a la credulidad del lector para acreditar un falso origen a la obra presentada. Un ejemplo podría hallarse en las Sergas de Esplandián, de Rodríguez Montalvo, pieza que pretende ser una continuación de la saga de Amadis. En ella se nos avisa de que lo que tenemos delante es la trascripción de un manuscrito encontrado en una tumba de piedra, enterrado a los pies de una ermita cercana a Constantinopla (Baquero, 2007-2008: 251)1. Incluso esta definición nos serviría para analizar el uso que del tópico hace Miguel de Cervantes en el Quijote, pues aun siendo una parodia y aun ensanchando sus límites, no deja de apelar al mismo principio de autenticidad histórica.

Ahora bien, la definición de Ana L. Baquero no es suficiente para explicar gran parte de la tradición más reciente de esta técnica narrativa, sobre todo, si tenemos en cuenta la originalidad y la amplitud con la que la emplean los autores a los que busca acercarse este artículo. Será necesario ensanchar los límites de dicha definición.

\section{José Jiménez Lozano y el don de la escritura}

José Jiménez Lozano encuentra en la narración una manera genuina de saber: "el conocimiento de lo humano y de lo histórico sólo podrá obtenerse por el oído, por la narración y el susurro" (Jiménez Lozano, 2003: 160). El relato, por tanto, es concebido como un camino epistemológico, en el sentido en el que lleva al autor hasta la aprehensión de lo real. Sin embargo, para el autor castellano no todos los relatos sirven a tales fines. Me refiero a lo que él llama los Grandes Relatos, a los que opone los relatos humildes y pequeños. El ejemplo al que Jiménez Lozano suele recurrir para explicar la diferencia entre ambos es a la decisión que el autor del Éxodo lleva a cabo al tomar como punto de partida las vidas de dos comadronas Siphrah y Puah, las cuales, recordemos,

1 Realizar una panorámica de la tradición del empleo del tópico del manuscrito hallado rebasa los objetivos de este texto. Para tal fin recomiendo: Baquero, 2007-2008 y García Gual, 2002. 
deciden desobedecer la orden del faraón de asesinar a cada bebé hebreo de sexo masculino: "El narrador [...] solo tiene ojos para ellas, [...] es ciego para los resplandores de la corte faraónica; [...] no le importan los nombres de los príncipes, ni la gloria entera de sus hazañas, sus Grandes Relatos guardados por sus escribas para memoria eterna" (Jiménez Lozano, 2003: 70-71). La elección del relato pequeño frente al Grande lleva en sí misma una decisión ética y estética. Ética porque decide alejar el foco del poderoso para centrarse en el débil, en el humilde y en el silenciado y estética porque dicha decisión afecta inevitablemente a los elementos (personajes, espacios, trama) de la propia narración.

Sabiendo esto, no debe extrañarnos que José Jiménez Lozano también conciba el oficio de escritor como una labor humilde. A pesar de que habla de quien se dedica a ella como "alguien que escribe y en cuya palabra encontramos hermosura, conocimiento y grosor de la humanidad, y que nos revela el lado de atrás de la realidad, no perceptible para los demás" no duda al decir que "esto es como si no hiciera nada" (Jiménez Lozano, 2005: 23). Dice esto porque la forma que tiene de entender la labor de la escritura es casi teológica: se trata de un don, pues todo le es regalado al escritor. Dicho de otro modo: la obra de un escritor no aparece espontáneamente de la nada, ni siquiera, como escribe, "de su carne y de su sangre" y "tampoco de su voluntad" (Jiménez Lozano, 2005: 24-25). Partiendo de estas premisas, el autor entiende que las historias y los personajes no tienen propiedad y que no pueden ser forzadas o retorcidas, sino que se han de tratar con sumo respeto. Más bien habría que dejarlos surgir, manifestarse y vivir en la página en blanco con total libertad sin que el yo venga a malear o a dotar a las palabras de sentidos ocultos. En un texto inédito publicado en su web lo explica de la siguiente forma:

Boris Pasternak recomendaba que, cuando se hacía la revisión de un poema, debía quitarse de él todo aquello que su autor estuviera seguro de ser capaz de volver a escribir, y dejar en el poema solamente aquello que no se sabía de dónde había venido, pero parecía que uno mismo no lo había escrito y era incapaz de hacerlo. Y, en la narración es sumamente obvio, para 
quien escribe, diferenciar lo que ha visto y oído de lo que él se ha inventado; y que pienso, como Pasternak, debe ser eliminado sin contemplaciones. Al fin y al cabo sólo se trata de la eliminación del "yo" del escritor, que, como afirmaron a la vez Monsieur Pascal y la "Gramática Razonada” de Port-Royal, no toleran "ni la civilidad ni la cristiandad". Ni la narración (Jiménez Lozano, "Pero también se nos regala el lenguaje”).

Aquí llegamos a un punto crucial de su poética. El escritor, entendido tal y como lo hace el novelista castellano, ha de alejar el yo de la narración puesto que éste es una suerte de agente contaminante que hace imposible la trasmisión de ese regalo que son las historias. Tal es así que, a modo de boutade, ha llegado a decir que se sentiría más satisfecho con sus libros si éstos no llevaran su nombre en la portada (Jiménez Lozano, 1983: 79). Reflejo de ello es que en sus novelas es muy común encontrarnos varios niveles de distancia entre el autor y la historia que se cuenta. Esta distancia puede aplicarse a través de personajes como ocurre en Retorno de un cruzado (2013), donde es el sobrino quien cuenta la historia del tío Pedro a través de recuerdos de conversaciones antiguas. $\mathrm{O}$, en otros casos, este distanciamiento se da a través del manuscrito hallado, como ocurre en Sara de Ur (1989) o en Libro de visitantes (2007).

En Sara de Ur (1989), a modo de epílogo, hallamos un capítulo que lleva por nombre "El sello del escriba". En él descubrimos que estamos ante un manuscrito encontrado, pues allí un narrador comenta la génesis de la historia que acabamos de leer. Y este narrador no es José Jiménez Lozano, sino una ficción, un escriba contemporáneo a Sara, que además de ser la protagonista nos remite al personaje bíblico homónimo que aparece en el Génesis. En el cierre de la novela, este narrador ficticio aprovecha para explicar las dificultades con las que se ha encontrado en la elaboración del manuscrito. De este modo, el Jiménez Lozano no solo se distancia creando un supuesto autor distinto a él mismo, sino que, por si aún cupiera alguna posibilidad de identificación entre a mbos, sitúa al escriba en un tiempo y en un espacio que nada tienen que ver con el tiempo y el espacio biográfico de José 
Jiménez Lozano. Pero "El sello del escriba" es, además, una poética en sí mismo. Allí pueden encontrarse muchos de los rasgos con los que unas líneas atrás definíamos el oficio de la escritura e incluso otros que resultan de gran interés. Me refiero a la parte en la que dice que para escribir la historia no solo ha tenido que seguir los pasos de Sara, viajar sufridamente y estudiar otros textos e idiomas sino que ha tenido que "entrar de aprendiz de platero y orífice, cardador, peraile, tejedor y tintorero, zapatero y tallador de piedras y cristales, perfumista, tañedor de arpa, pocero y pastor o peluquero para estimar por mí mismo los informes sobre el ajuar y costumbres de mujeres" (Jiménez Lozano, 1989: 119) y más tarde, en una discusión en la que el narrador tiene con un padre que le recomienda a su hijo que se haga escriba, dado que es un oficio mucho más llevadero que la carpintería, que la orfebrería, que la barbería, que la alfarería, nuestro narrador responde: "No hagas caso a tu padre. Peor es ser escriba, porque tendrás que padecer todos esos oficios para poder escribir" (Jiménez Lozano, 1989: 122). De nuevo, está aquí la idea de que la escritura no puede ser un ejercicio solipsista sino que ha de contener un cúmulo de alteridades como lo son, en este caso, todos los otros oficios que no son propiamente el de escritor.

Otra novela donde aún queda más patente, si cabe, esta voluntad de distanciamiento del yo es Libro de visitantes (2007). En ella, también al cierre, encontramos la "Nota del traductor-editor", un epílogo en que referencia a un prototexto -un texto anterior al que tenemos acceso y que solo podemos conocer a través de las menciones que se hacen en el texto presente- encontrado en una biblioteca del Monte Athos por un viajero inglés que lo recogió y tradujo. Y el mentado viajero inglés, a su vez, dejó escrito otro apéndice que apuntaba a un prototexto aún más antiguo, esta vez con la autoría de un mercader de oriente o de un funcionario romano, ambos personajes presentes en el desarrollo de Libro de visitantes. En este libro, José Jiménez Lozano hace algo parecido que en Sara de Ur. Crea otros narradores que no comparten ni espacio ni tiempo con él, pero en este caso el alambicamiento y el grado de capas a modo de traducciones, transducciones y reescrituras sitúa entre sí y la historia que se cuenta es tal que merece la pena 
que nos detengamos en enumerarlas. Si repasamos el recorrido del manuscrito hasta llegar a ser publicado, deberíamos reparar en los siguientes niveles: el relato es a) primeramente escrito por un mercader de Oriente o un funcionario romano; b) es atesorado en una biblioteca durante siglos; c) es editado y traducido por un viajero inglés y finalmente d) vuelto a editar y traducir por un "editor-traductor" que no firma su nota y que no necesariamente deberíamos identificar con José Jiménez Lozano.

\section{Vicente Luis Mora y el invasivo tumor del yo}

La concepción que Vicente Luis Mora tiene de la literatura difiere en muchos puntos de la de José Jiménez Lozano. Mientras que en el caso del autor castellano podríamos hablar de la búsqueda de una mímesis de lo real, Mora se acerca más al juego y a la experimentación con lo verosímil. Simplificando mucho: más que una búsqueda de lo puramente real, está más interesado en aquello que puede pasar por real, de ahí su interés por la falsificación y el hoax. De hecho, a la hora de referirse a la novela que trataremos a continuación, Alba Cromm (2010), Teresa Gómez y Carmen Morán han escrito que ésta conecta con el mensaje "de toda una nueva generación de escritores interesados en constatar los extraños perfiles que la realidad adquiere en el mundo contemporáneo, por la virtualidad, el simulacro y el no lugar" (Gómez Trueba, Morán Rodríguez, 2017: 84). Y estas palabras podrían complementarse con otras que el mismo Mora publicó en su blog:

Escribir puede presentarse también como un modo de intervenir en lo real, de cuestionar nuestro mundo y también nuestra forma de pensarnos escritores o artistas. La literatura, como dijo Arnold hablando de la poesía, puede ser una crítica de la vida, y también una crítica de la crítica, y una vivencia artística de la vida (Mora, 2010c).

Si tuviéramos que extraer una síntesis de estas dos citas tendríamos que referirnos al interés de Vicente Luis Mora por lo especular y lo metaficcional; interés del que se deriva casi de manera 
inevitable su preocupación por el manuscrito hallado. Y es que esta herramienta resulta idónea como campo de experimentación: el empleo del tópico cervantino supone la elaboración de un simulacro ya que todo manuscrito hallado implica origen ficticio del texto en cuestión. Esto nos lleva inevitablemente al cuestionamiento de los límites formales de la novela o, dicho de otro modo, nos obliga a reflexionar sobre la naturaleza narratológica de la obra en cuestión. A estas dos razones habría que añadirle aún una última no menos importante: la disolución del yo en lo que se narra:

La técnica del manuscrito encontrado es literariamente muy rentable, y funciona bien a escritores que, como un servidor, descreen del decimonónico narrador omnisciente. El narrador omnisciente $[. .$.$] era un recurso un poco infantil para soste-$ ner la historia, y venía de la omnisciencia divina, por un lado, y en la creencia en un Yo sólido por otro, travestido en un Él capaz de contar una historia (o una vida, o el Mundo) por sí solo. El manuscrito encontrado enfrenta al lector directamente con los personajes y con la historia, y no hay más interlocutores que diversas formas técnicas de disolución del autor en la trama (Mora, 2008).

Ahora bien, antes de pasar al análisis del uso del tópico en Alba Cromm, es conveniente dar algunas pinceladas acerca de la forma de la obra. La novela emula tanto la apariencia visual como la estructura de una revista para hombres llamada Upman, en el número monográfico que le dedican a la agente de policía Alba Cromm, conocida por haber resuelto con éxito un caso de ciberdelincuencia y pederastia. La novela abre con el editorial, en el cual se nos dice que es el reportero Ramírez el encargado de recopilar y reordenar todos los documentos y testimonios del caso. El grueso de la novela es la consecución de notas de diario de la propia Alba Cromm, entradas de su blog, cuadernos de notas y diarios de otros personajes, informes policiales, trascripciones de conversaciones, noticias y reportajes que recogidos en el dosier componen de manera polifónica y fragmentaria el desarrollo de 
la trama. Por fuera, Alba Cromm es un volumen más editado por Seix Barral y firmado por Vicente Luis Mora, pero por dentro el simulacro es evidente. Intercalados en el dosier de la revista descubrimos bloques publicitarios, columnas de opinión dispuestas con ladillos y subtítulos, información sobre la programación televisiva, entrevistas e incluso un avance de lo que se publicará en el próximo número de Upman.

Es cierto que en la obra no hay como tal un manuscrito encontrado, más bien tendríamos que hablar de una actualización del mismo tópico ya que, como bien explican Teresa Gómez y Carmen Morán, "se produce un alejamiento de la instancia narrativa merced a un truco metanarrativo que convierte la obra en una obra dentro de una obra: Alba Cromm es la novela y es la revista contenida en la novela e identificada especularmente con ella" (Gómez Trueba, Morán Rodríguez, 2017: 84). Esto, dicho de otro modo, viene a significar que por la similitud con una revista en la disposición de los paratextos y la organización del contenido se produce una identificación entre la novela (de Viente Luis Mora y editada en Seix Barral) y la revista Upman, de modo que nosotros, los lectores, recibimos ambas de manera simultánea. Ya no hay un traductor o un editor que nos explique que ha hallado dicho texto y que lo ha dispuesto para que lo leamos sino que Alba Cromm, dada su apariencia de revista, trae implícito el que alguien ha clasificado, ordenado y editado determinados prototextos. No necesita de epílogos o de prólogos cervantinos dado que todo lo que se podría contar en ellos está codificado en la propuesta formal y estructural de Upman.

Vicente Luis Mora no solo suprime la figura del editor o del traductor, tan común en la implementación del manuscrito hallado, sino que parece convertir la ausencia de narradores en su propuesta narratológica. En esta línea habría que ubicar la pregunta que lanzó en la entrada de blog en la que presentaba la novela. “¿quién es el narrador de Alba Cromm?” (Mora, 2010b). La novela, como ya adelantábamos antes, es un compendio polifónico orquestado con bastante acierto. Como si se tratara de una obra cubista, se nos of recen distintos fragmentos de distintos focos y ángulos que dan como resultado una suerte de poliedro 
narrativo. Y esta pretensión poliédrica es un rasgo constitutivo de la poética de esta obra y de otras como Fred Cabeza de Vaca (2017). Sin ir más lejos, en las adendas y artículos que hay intercalados en las páginas de la revista Upman, hallamos pistas que lo apuntalan. Un tal V.L. Vargas Llosa escribe en la sección "Parrafadas (literatura cúbica)": "No conozco [...] las cualidades que hacen a un libro perfecto [...] pero sé que uno de sus requisitos incuestionables es que no puede estar escrito por un solo hombre" (Mora, 2010a: 89), y más adelante, hallamos otra pista en una falsa reseña escrita por Anneo Mónadus sobre Pienso ego existo. La literatura egódica y el narcisismo existencial, de Decira Nómalo, libro que se parece sospechosamente en el título y el tema al ensayo que el propio Vicente Luis Mora publicaría cuatro años más tarde: $\mathrm{La}$ literatura egódica. El sujeto narrativo a través del espejo (2014). En la reseña se define la literatura egódica como aquella en la que yo invade la obra como un tumor maligno (Mora, 2010a: 124).

En definitiva, en Alba Cromm, Vicente Luis Mora emplea el tópico del manuscrito encontrado para orquestar una novela polifónica ${ }^{2}$ donde el yo, aparentemente, se disuelve en multitud de instancias, personajes, voces y géneros. De manera diferente, pero con la misma finalidad, dos autores con concepciones de la literatura tan dispares como lo son José Jiménez Lozano y Vicente Luis Mora, han encontrado en el viejo tópico cervantino una herramienta para evitar que el yo se inmiscuya en las historias que cuentan.

\section{Bibliografía}

Baquero Escudero, A. (2007-2008). “Un viejo y persistente tópico literario: el manuscrito hallado”, Estudios Románicos. Vol. 16-17, 249-260.

2 Teresa Gómez Trueba y Carmen Morán Rodríguez exploran la idea de que el verdadero logro de Alba Cromm es la capacidad de presentar voces anónimas y carentes de identidad tal y como ocurre en las redes y en la mayoría de espacios de internet. Para profundizar en ello, pueden consultarse las páginas 255 y 256 de Hologramas. Realidad y relato del siglo XXI (2017). 
Gómez Trueba, T., Morán Rodríguez, C. (2017). Hologramas. Realidad y relato del siglo XXI. Valladolid: Trea.

Jiménez Lozano, J. (1983). “Desde mi Port-Royal”. Anthropos, 25, 79. Jiménez Lozano, J. (1989). Sara de Ur. Barcelona: Anthropos.

Jiménez Lozano, J. (2005). El narrador y sus historias. Madrid: Publicaciones de la residencia de Estudiantes.

Jiménez Lozano, J. (2007). Libro de visitantes. Madrid: Encuentro. Jiménez Lozano, J., "Pero también se nos regala el lenguaje", [en línea] <http://www.jimenezlozano.com/v_portal/informacion/informacionver957f.html? cod $=192 \&$ te $=83 \&$ idage $=199 \&$ vap $=0>$ [12.10.2018].

Mora Suárez-Varela, V. (2008). "Cloverfield, Ana Merino, Lolita Bosch, Fernández Buey”, [en línea] <http://vicenteluismora. blogspot.com.es/2008/01/cloverfield-ana-merino-lolita-bosch. html> [18.10.2018].

Mora Suárez-Varela, V. (2010a). Alba Cromm. Madrid: Seix Barral.

Mora Suárez-Varela, V. (2010b). “Alba Cromm”, [en línea] <http:// vicenteluismora.blogspot.com.es/2010/04/alba-cromm.html> [18.10.2018].

Mora Suárez-Varela, V. (2010c). "El hoax de Quimera”, [en línea] <http://vicenteluismora.blogspot.com.es/2010/09/el-hoax-de-quimera.html $>$ [18.10.2018]. 